\title{
NOTES AND CORRESPONDENCE
}

\section{Bottom Temperatures Related to Gulf Stream Displacement off the Southeast United States Shelf}

\author{
LI LI ${ }^{1}$ AND MARK WIMBUSH \\ Graduate School of Oceanography, University of Rhode Island, Kingston, RI 02881
}

10 July 1984 and 20 September 1984

ABSTRACT

\begin{abstract}
Bottom temperature time series recorded beneath the Gulf Stream at 265 and $589 \mathrm{~m}$ depth off the Georgia coast are compared with simultaneous time series of main thermocline depth determined from inverted echo sounder and bottom pressure gauge records at the same sites. Bottom temperature is found to be coherent with vertical displacement of the thermocline, suggesting that bottom temperature under the Gulf Stream front is a potentially useful indicator of Gulf Stream displacement. Additional evidence is provided by the similarity of bottom temperature and thermocline depth coherences with longshore current at the shelf break. Bottom temperature at the deeper station appears to be the better indicator of Gulf Stream meandering for periods longer than five days.
\end{abstract}

\section{Introduction}

It has long been known that the path of the Gulf Stream meanders, and that this meandering has important effects: it causes, for example, fluctuating currents on the outer countinental shelf (Lee and Brooks, 1979). Monitoring the path of the Gulf Stream is, however, not straightforward. Conventional hydrography reveals the full three-dimensional structure, but it is too labor-intensive and costly for time series monitoring purposes. Infrared imagery from satellites is commonly used today, but it has three drawbacks: it represents only what is happening at the ocean surface, it is often unusable in summer because of poor temperature contrast, and, most importantly, it is hampered by cloud cover so that the data obtained is intermittent.

Recently an acoustic technique has been developed to monitor the main thermocline depth from the sea floor (Watts and Rossby, 1977). Inverted echo sounders (IESs) employing this technique have been used to monitor meandering of the Gulf Stream downstream of Cape Hatteras, and comparison of IES estimates with XBT estimates of Gulf Stream position in that region has shown that there is an rms difference of only $8 \mathrm{~km}$ (Watts and Johns, 1982). Combining the IES with a bottom pressure gauge refines the technique by eliminating barotropic effects (Watts and Wimbush, 1981). Using an IES and a bottom pressure gauge to record Gulf Stream displacement,

\footnotetext{
' Permanent address: Third Institute of Oceanography, National Bureau of Oceanography, Xiamen, People's Republic of China.
}

Li et al. (1985a) studied the relationship of longshore current variability over the Georgia shelf to Gulf Stream forcing. Their results confirm previous ideas about the influence of the Gulf Stream on shelf circulation.

While the IES is clearly able to provide a reliable record of Gulf Stream position, it is worth considering whether other simpler measures might be used instead. In the following section we compare bottom temperature records on the continental slope with acoustically measured Gulf Stream displacement, during an 80day period in winter and early spring.

\section{Data}

Two moorings were located on a cross-shelf section $\left(108^{\circ}\right.$ true) on the continental slope off Savannah, Georgia from 22 January-12 April 1978. Mooring $H$ was located at the $265 \mathrm{~m}$ isobath and I at the $589 \mathrm{~m}$ isobath (Fig. 1). Round-trip acoustic travel time, bottom pressure and bottom temperature were recorded at each site. A number of current meter records were obtained on the continental shelf by Dr. T. N. Lee of the University of Miami during the same period. We use his mooring E current record from $17 \mathrm{~m}$ depth at the shelf break (75 m isobath) on the same cross-shelf section (Fig. 1), since this record is most strongly influenced by the Gulf Stream (Li et al, 1985a). We also make use of the temperature records from 17 and $72 \mathrm{~m}$ depth on the same mooring. All time series were processed in the manner described in $\mathrm{Li}$ et al. (1985a). In particular, the acoustic travel time and bottom pressure records were 


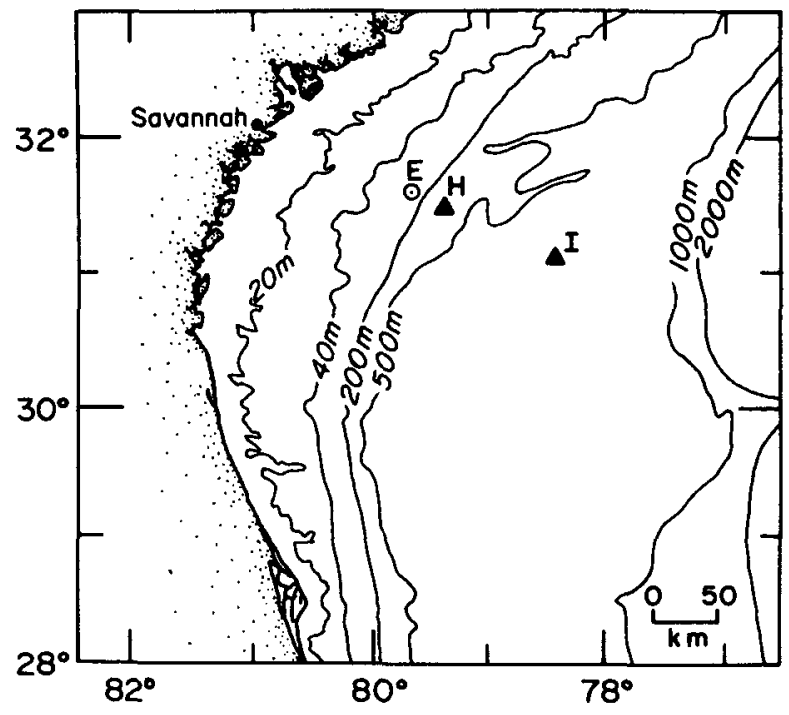

FIG. 1. Locations of IES moorings $H$ and $I$, and current meter mooring $\mathrm{E}$.

used, according to the method of Watts and Wimbush (1981), to infer main thermocline depth $d$ (taken to be the depth of the $16^{\circ} \mathrm{C}$ isotherm at site $\mathrm{H}$ and the $15^{\circ} \mathrm{C}$ isotherm at site $\mathrm{I}$ ); and the longshore current $v$ was computed as the component flowing toward $30^{\circ}$ true.

\section{Results and discussion}

Subtidal time series of bottom temperature $T$ and thermocline depth $d$ at sites $\mathrm{H}$ and $\mathrm{I}$ are presented in Fig. 2. The upper water column longshore current $v$ at the shelf break is also shown for comparison.

Correlation between $T$ and $d$ for each site can be clearly seen in the figure. The computed $T, d$ correlation coefficient is 0.73 at $\mathrm{H}$ and 0.63 at $\mathrm{I}$. At both sites bottom temperature shows a strong $\sim 12$ day oscillation which coincides with the fundamental fluctuating cycle of the thermocline. Shorter period fluctuations in $T$ and $d$ appear somewhat related at site $\mathrm{H}$ and unrelated at site $\mathrm{I}$. At site $\mathrm{H}$, longer period (50-70 day) divergence between the $T$ and $d$ traces appears to be responsible for most of the degradation in correlation. We believe that it is caused by a filament of Antarctic Intermediate Water (Atkinson, 1983) which was intermittently present at site $H$ during the first ten and last thirty days of our observations (Li et al., 1985b).

These observations are in accord with the results of spectral analysis. Figure 3 shows the coherencesquared $R^{2}$ and relative phase of $T$ and $d$ for both stations. At site $\mathrm{H}$ the coherence is significant $(95 \%$ confidence bar above $R^{2}=0$ ) throughout the subtidal band except for the 1.25-day period. A secondary low coherence band appears at four days. At site I the coherence is high for periods longer than three days, with no significant coherence at short periods. At both sites, $T$ and $d$ have a relative phase close to $0^{\circ}$ at all frequencies where the coherence is significant. This means that increasing bottom temperature is associated with a westward drift of the Gulf Stream and deepening of the thermocline (as expected).

These results all indicate that bottom temperature measured on the continental slope beneath the Gulf Stream is closely related to main thermocline depth and hence to meandering of the Gulf Stream. Bottom temperature near the $600 \mathrm{~m}$ isobath is an indicator of Gulf Stream lateral movement for period longer than three days while bottom temperature near the $250 \mathrm{~m}$ isobath has a broader coherent band (period $>1.4$ days). At the dominant $\sim 12$-day period the deeper site shows the higher local $T, d$ coherence.

To investigate the possibility of using bottom temperature beneath the Gulf Stream as a measure of its influence on shelf circulation, the coherences of longshore current at the shelf break with these measured bottom temperatures and thermocline depths were computed (Fig. 4). At I the coherence with bottom temperature was very similar in form to the coherence with thermocline depth, being insignificant at periods shorter than five days and rising to a peak of $R^{2}$ $=0.5$ at a 12.5 -day period. At $H$ the coherence with

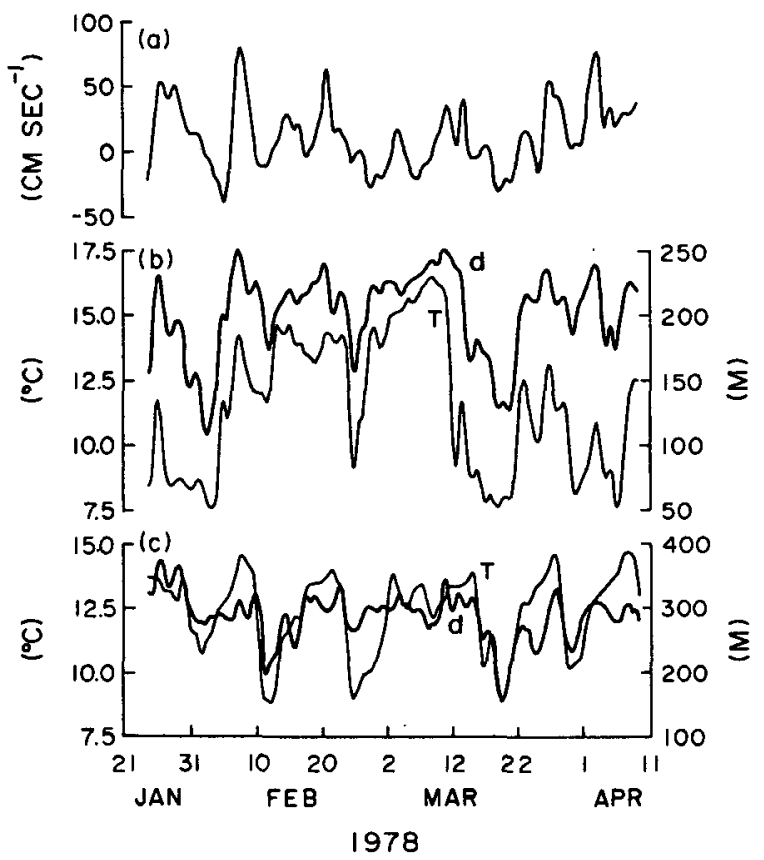

Fig. 2. (a) $v$ at $17 \mathrm{~m}$ depth at site $\mathrm{E}$; (b) $d_{16^{\circ} \mathrm{C}}$ and $T$ at site $\mathrm{H}$; (c) $d_{15^{\circ} \mathrm{C}}$ and $T$ at site I. Scales in $\mathrm{b}$ and $\mathrm{c}$ are the same for $T$ but different for $d$, being chosen to clarify the similarity between the $d$ and $T$ time series. 

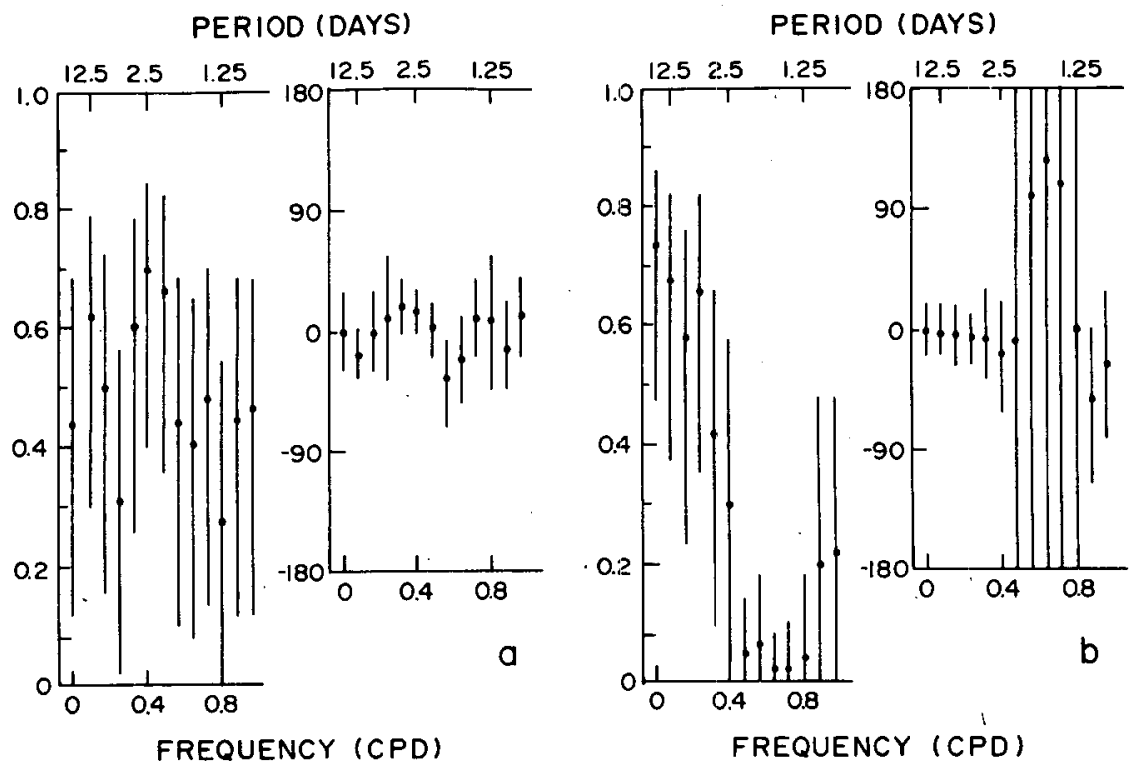

FIG. 3. Coherence-squared and relative phase of $T$ with $d$ for (a) site $\mathbf{H}$; (b) site I. The dots show the estimated values and the bars show the $95 \%$ confidence intervals. Positive phase implies $d$ leads $T$.

bottom temperature is generally lower than that with thermocline depth, but it shows two significant peaks centered on the 12.5- and 2.5-day bands. It has been shown that these are the most energetic bands of Gulf Stream forcing during the mooring period $(\mathrm{Li}$ et al., 1985a).

\section{PERIOD (DAYS)}
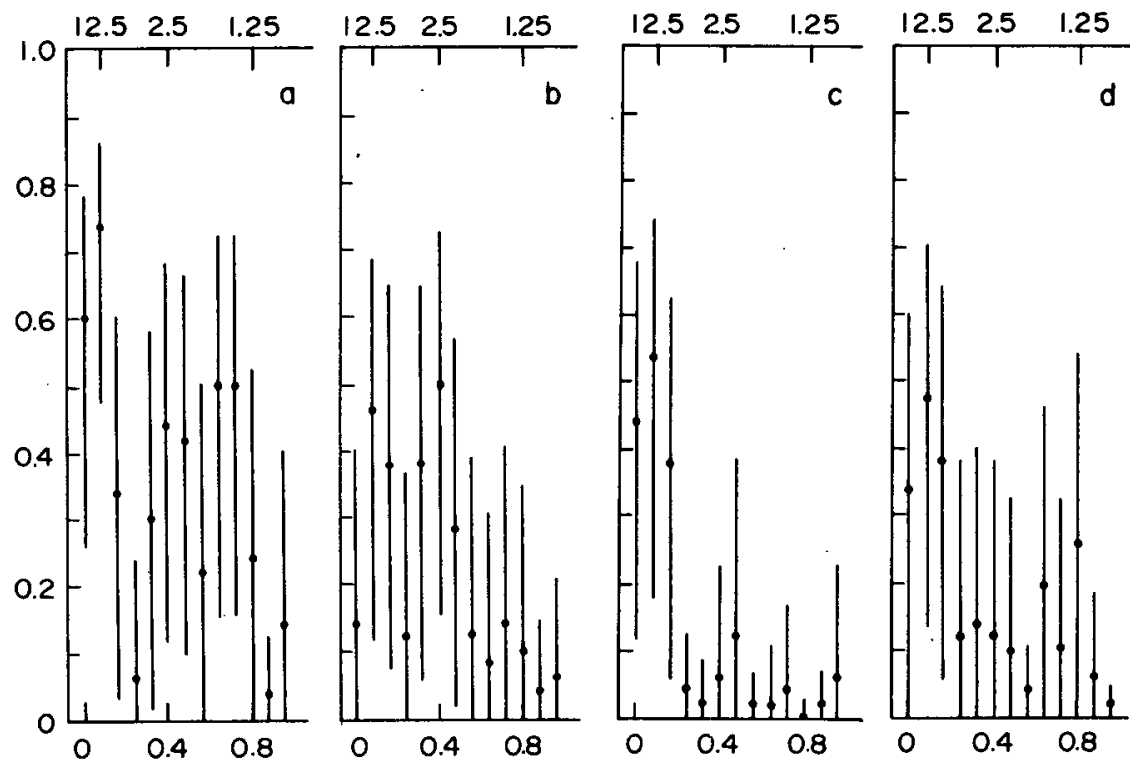

FREQUENCY (CPD)

FIG. 4. Coherence-squared of (a) $v$ with $d_{H}$; (b) $v$ with $T_{H}$; (c) $v$ with $d_{I}$; (d) $v$ with $T_{I}$. The dots show the estimated values and the bars show the $95 \%$ confidence intervals. 
Our observations are consistent with the occurrence, on the cyclonic side of the Gulf Stream, of frontal eddies and associated upwellings. These eddies, observed from the Florida Straits to Cape Hatteras, follow passage of the shoreward crest of a meander and cause upwelling from about 300 meters depth (Lee et al., 1981; Pietrafesa and Janowitz, 1980). Presumably they are mainly responsible for the fact that the 12.5-day $R^{2}=0.5$ coherence of $d_{H}$ with $d_{I}$ is not higher.

At either site, bottom temperature $T$ is coherent with thermocline depth $d$. But $T$ is not significantly coherent between sites: maximum computed coherence $R^{2}=0.26$ occurs in the 6.3-day band, but this is lower than the $95 \%$ significance level; at the most energetic 12.5 -day band, $R^{2}$ is only 0.24 . It appears that $T$ at site $\mathrm{H}$ and $T$ at site $\mathrm{I}$ are only related through their local coherences with $d$ and the coherence of $d$ between the two sites: in the 12.5-day band,

$$
\begin{aligned}
R_{T d(H)}^{2} \times R_{d(H) d(I)}^{2} \times R_{T d(I)}^{2} & =0.62 \times 0.5 \times 0.68 \\
& =0.21,
\end{aligned}
$$

which is nearly the same as the observed

$$
R_{T(H) T(I)}^{2}=0.24 \text {. }
$$

Of the two thermocline depth records, that at site I is probably the better representation of overall Gulf Stream meandering, since it is not affected by frontal eddies. However the record of $d$ at site $\mathrm{H}$ has the higher coherence with the shelf break current record $v$, implying that these currents are affected by the frontal eddies.

The above results show a vertically correlated thermal structure indicating a total water column response to Gulf Stream meandering, at least out to the $600 \mathrm{~m}$ isobath off the Georgia coast. The relationship of main thermocline depth and near-bottom temperature is discussed by Li et al. (1985b). They found that $d_{H}\left(d_{I}\right)$ can be expressed as a linear function of $T_{H}\left(T_{l}\right)$ when the bottom temperature is higher than $9^{\circ} \mathrm{C}$. The relationship is also linear when $T_{H}\left(T_{I}\right)<9^{\circ} \mathrm{C}$; however the slope is then larger. The estimated range of thermocline depth variation for a given bottom temperature is $\pm 40 \mathrm{~m}$ for station $\mathrm{H}$, corresponding to a standard deviation of $\sim 25 \mathrm{~m}$. This indicates a standard deviation of Gulf Stream lateral displacement of $\sim 5 \mathrm{~km}$, according to the mean cross-stream thermal structure given by Olson et al. (1983). The standard deviation at site $\mathrm{I}$ is larger than that at $\mathrm{H}$ by a factor of 2 .

In summary, our analysis suggests that, with suitable "calibration," Gulf Stream meandering may be monitored through measurements of either thermocline depth or bottom temperature. While the former, being more directly related to Gulf Stream position, is scientifically the preferred measurement, the latter, being relatively simple and inexpensive to perform, is sometimes easier to carry out. We expect this technique to work well in areas where the Gulf Stream is in contact with the bottom, i.e., Florida Straits to Cape Hatteras. Strong vertical correlation of temperature is observed by Mooers and Brooks (1977) at the $\sim 200 \mathrm{~m}$ isobath on both sides of the Straits of Florida through the bulk of the water column. Vertically correlated Gulf Stream thermal structure is also reported by Lee and Waddell (1983) at $30^{\circ} \mathrm{N}$, and by Brooks and Bane (1983) off the North Carolina coast. Even to the east of Cape Hatteras, where the Gulf Stream flows in deep water, a correlation is observed (Johns and Watts, 1985; Watts, 1983): the temperature $500-1000 \mathrm{~m}$ above the bottom in $3000-3700 \mathrm{~m}$ depths is positively correlated with thermocline depth variations due to meandering of the Gulf Stream overhead.

Since most current meters also record temperature, this information will frequently be available as a byproduct of a current measuring program. It is likely that temperatures measured above bottom are even more strongly related to Gulf Stream position. Indeed a vertically averaging temperature sensor, such as a resistance wire extending through the thermocline, would minimize the influence of small-scale structure on the temperature measurement, and it might be as effective as an IES with pressure gauge in monitoring the Gulf Stream. However the possibility of monitoring Gulf Stream position from temperature measurements does not appear to extend to temperatures measured on the shelf: no significant coherence was observed between $d$ at site $\mathrm{H}$ and temperatures recorded at site $\mathrm{E}$.

Acknowledgments. Funding was provided by Department of Energy Contract DE-AS05-76EV05163 and the Minerals Management Service prime Contract AAT851-CT1-25 to Science Applications Inc., Raleigh, NC, subcontract 11-82029-11. Tom Lee kindly let us use his current meter data. We have had the benefit of discussions with Tom Rossby and Randy Watts.

\section{REFERENCES}

Atkinson, L. P., 1983: Distribution of Antarctic Intermediate Water over the Blake Plateau. J. Geophys. Res., 88, 4699-4704.

Brooks, D. A., and J. M. Bane, 1983: Gulf Stream meanders off North Carolina during winter and summer 1979. J. Geophys. Res., 88, 4633-4650.

Johns, W. E., and D. R. Watts, 1985: Gulf Stream meanders: Observations on the deep currents. J. Geophys. Res., (in press).

Lee, T. N., and D. A. Brooks, 1979: Initial observations of current, temperature and coastal sea level response to atmospheric and Gulf Stream forcing on the Georgia shelf. Geophys. Res. Lett., 6, 321-324. 
--, and E. Waddell, 1983: On Gulf Stream variability and meanders over the Blake Plateau at $30^{\circ} \mathrm{N}$. J. Geophys. Res. 88, 4617-4631.

$\longrightarrow$, L. P. Atkinson and R. Legeckis, 1981: Observations of a Gulf Stream frontal eddy on the Georgia continental shelf, April 1977. Deep-Sea Res., 28A, 347-378.

Li, L., M. Wimbush, D. R. Watts, A. J. Brincko and T. N. Lee, 1985a: Gulf Stream and wind induced current variability on the Georgia continental shelf, winter 1978. J. Geophys. Res., 90, 3199-3210.

,,---- and T. N. Lee, 1985b: Variability of thermal structure off Georgia, Winter 1978, Continental Shelf Res. (submitted)

Mooers, C. N. K., and D. A. Brooks, 1977: Fluctuations in the Florida Current, summer 1970. Deep-Sea Res., 24, 399-425.

Olson, D. B., O. B. Brown and S. R. Emmerson, 1983: Gulf Stream frontal statistics from Florida Straits to Cape Hatteras derived from satellite and historical data. J. Geophys. Res., 88, 45694577.

Pietrafesa, L. J., and G. S. Janowitz, 1980: On the dynamics of the Gulf Stream front in the Carolina capes region. Proc. Second Int. Symp. on Stratified Flows. Trondheim, Norway, Tapir $2 \mathrm{v}$, 1095 pp.

Watts, D. R., 1983: Gulf Stream variability. Eddies in Marine Science, Springer-Verlag.

- - and H. T. Rossby, 1977: Measuring dynamic heights with inverted echo sounders: Results from MODE. J. Phys. Oceanogr., 7, 345-358.

depth variation measured from the sea floor. Proc. Int. Symp. on Acoustic Remote Sensing of the Atmosphere and Oceans, University of Calgary, Calgary, Alberta, Section III, 33-47.

- - , and Johns, W. E., 1982: Gulf Stream Meanders: Observations on propagation and growth. J. Geophys. Res., 87, 9467-9476. 